\title{
Consumer Awareness of the Use of Food Labels in Lagos State, Nigeria
}

\author{
Samuel T. Danilola ${ }^{\mathrm{a}}$, Olubunmi A. Omotesho ${ }^{\mathrm{a}}$, And Jubril Animashaun ${ }^{\mathrm{a}}$ \\ ${ }^{a}$ Department of Agricultural Economics and Farm Management, University of Ilorin, Kwara state, Nigeria \\ ${ }^{*}$ Corresponding author \\ samueldanilola@yahoo.com \\ TEL: +2348068569911
}

Received: 14 June 2018; Published online: 18 October 2019

\begin{abstract}
The increase in relative level of education and the growing middle-class income earners in Nigeria have made packaged food items attractive to consumers. These foods provide handy, nutritious and convenient food for consumers; however, they also come with public health concerns. From a policy perspective, food labelling can gauge consumers' response to the safety conditions of packaged food. However, understanding consumers' awareness and the use of food label information has attracted little research attention in many developing countries in sub-Saharan Africa. In this study, we investigated consumers' awareness of the use of food safety labels in Lagos state, Nigeria. We used primary data collected using pretested structured questionnaire from 220 food shoppers who bought pre-packaged foods. A two-stage sampling technique was used to select the respondents. Consumers' awareness and use of food safety information was revealed using descriptive statistics; Ordinal Regression Analysis was used to examine the socioeconomic factors determining the frequency of reading food safety labels. We found evidence of the influence of socioeconomic characteristics on how consumers read food labels. The study therefore recommends that there should be continuous awareness campaigns on the importance of food labels in ensuring safety and food producers should make sure their food labels are legible.
\end{abstract}

Keywords: Food label; Food safety; Nigeria; Ordinal Regression; Pre-packaged food

\section{Introduction}

Globalization, the demand for healthy food and the significant progress in food science and technology have resulted in an increase in the consumption of imported pre-packaged foods and local food producers following internationally acceptable standards. In addition, because the change in food and consumption lifestyle often comes with public health concerns, regulators often emphasize the use of food labelling to address the health concerns that may arise from the changing food lifestyle. Food labelling enables local consumers to make informed decisions on food choices. In many countries, food prod- uct labelling is a policy tool used by regulators to gauge the response of consumers to health information and is used by food companies for product differentiation strategy (Kaur, Nirmal Kaur, \& Neha Qumar, 2016). Unlike in many industrialized countries, there have been very few studies in Nigeria on consumers' awareness of food labelling.

According to a report by the Office of Agricultural Affairs of the USDA/Foreign Agricultural Service in Lagos, Nigeria (David, 2009), the National Agency for Food and Drug Administration and Control (NAFDAC) has been empowered by law - Government of Nigeria Act No 19 of 1993 (as amended) and the Food and Related 
Products (Registration) Act No. 20 of 1999 - to bring up standards for food production as well as laws against food commodities that are deleterious to human health. NAFDAC regulations require that food labels be detailed and exact, and not fraudulent or misleading:

- Listed below are the outline of the minimum labelling requirements of NAFDAC:

a) A product's brand name must be in bold letters.

b) Name and detailed "location" address of the manufacturer showing country of origin must be provided on the product label.

c) The batch number, date of manufacture and best before/expiry date should be written.

d) Net content, specifying essential ingredients in standard weight for solids and standard volume for liquids should be written.

e) Ingredients must be listed by their public names in order of their prominence by weight.

f) Food additives and colours must be written, if present, on the label. Spices, flavours and colours may be listed as such, without naming the specific material, but any artificial colour or flavour should be identified as such.

g) NAFDAC's registration number must be a part of the information on the product label. Labelling should be in English. If it is in another language, an English transcription has to be provided on the label or package insert (where applicable).

- Stick-on labels meeting NAFDAC requirements are permitted provided they don't remove easily.

- Foreign labels must be affixed prior to the product arrival at the Nigerian port of entry.

- Foreign labels must be applied prior to export.
- Sample-size products or institutional packed products have no special labelling requirements.

- For production and expiry dates, the day is written before the month.

- NAFDAC regulation stipulates that all food products should carry best-before dates and/or shelf life on their packaging. The regulation states that the expiry date should be "at least half the shelf life as at time of inspection." This implies at the time of inspection (by NAFDAC after clearing Customs), that the period from the inspection date until the expiration date should be equal to or greater than half of the total shelf life of the product (date of production until expiry):

- NAFDAC does not grant exceptions to labelling requirements

With respect to Nutritional Labelling, the specific requirements include:

- NAFDAC accepts the standard U.S. nutritional fact panel.

- Every nutritional claim on a product's label must be warranted. Nutritional labelling is obligatory for any pre-packaged food item for which the manufacturer makes a nutrition or dietary claim.

- Foods for special dietary uses with claims of disease prevention, treatment, mitigation, cure or diagnosis must comply with NAFDAC's guidelines for registration of drugs and be registered as medicinal products or nutriceuticals. Labels must contain directions for safe usage.

- Additional nutritional labelling information is voluntary.

In addition, the regulations guiding the use of food additives are also indicated in the Government of Nigeria Act 19 of 1993. For example, NAFDAC requires the fortification of wheat and maize flour, vegetable oil and sugar with Vitamin A, while salt must be iodized. NAFDAC applies the food additive standards of the Codex Alimentarius Commission, EU and FDA in its assessment of food safety: 
- No person may manufacture, import, advertise, sell or present any food item or beverage containing a non- nutritive sweetener for human consumption unless the product is "specified for special dietary usage."

- Non-nutritive sweeteners, including saccharin and cyclamates, may be used in lowcalorie, dietary foods/beverages but are not permitted in any food or beverage to be consumed by infants or children.

- Potassium bromate as a bread improver is not permitted. Other several bread improvers are now available.

As at the time of this study, Nigeria had no laws regulating products of biotechnology. However, a draft biosafety bill has been developed and is before the National Assembly for consideration. The draft bill advocates compulsory labelling of food items containing products of biotechnology to protect consumers' right to know. When the bill is passed, NAFDAC will be the enforcing agency.

The extant literature has focused on the importance of reading food labels due to its role as a major source of information on food to consumers (Grunert \& Wills, 2007) Other literature has identified how food labels inform consumers' purchasing behaviour (Henson \& Caswell, 1999; Naspetti \& Zanoli, 2009; Ortega, Wu, Wang, \& Widmar, 2011; Rijswijk \& Frewer, 2008; Smith \& Riethmuller, 2000) in developed countries. Together, these studies provide evidence that gaps still exist in research about how consumers respond to threats of unsafe foods in the global food market and if it influences their use of food labels during purchases in developing countries like Nigeria.

There is evidence of the effect of some socioeconomic characteristics on the use of food labels around the world. For example, the studies by Basarir (2012), Du Plessis and Rousseau (2003), Ali and Kapoor (2009), Wyma et al. (2012), Talagala and Kalukottege (2015) and Ezeh and Ezeh (2014) highlight the importance of education, gender, and income in promoting the use of food labels. However, there is no empirical study on the factors influencing the frequency of using food labels in Nigeria. For example, Falola
(2014) studied the willingness to pay for food labels, and Ezeh and Ezeh (2014) only studied the attitude of students of higher education institutions towards food label information. These leave some gaps in knowledge that this study was designed to fill.

Therefore, in this study we investigated the level of awareness and use of food safety labels; identified the socioeconomic and psychological factors influencing the awareness, and use of food safety information on labels, and the constraints to the use of food label information before food purchase.

\section{Materials and Methods}

\subsection{Study Area}

This study was conducted in Lagos state, southwest Nigeria. Lagos is geographically positioned on longitude $2^{\circ} 42^{\prime}-4^{\circ} 20^{\prime}$ East and latitude $6^{\circ} 22^{\prime}-6^{\circ} 42^{\prime}$ North. It is surrounded on the West by the Republic of Benin, the North and East by Ogun State and on the South, the Atlantic Ocean (Lawal \& Aliu, 2012).

Lagos, according to World population review website, is the largest city in Africa and Nigeria Population Commission estimates its population to be about 21 million people (World Population Review, 2016) and it produces less than $10 \%$ of the food that is consumed in the city (Mhango, 2013). Being the commercial city of Nigeria, it is home to virtually all ethnic groups in Nigeria and it has the smallest land area, 356,861 ha, of all the states in Nigeria, of which 75,755 ha is marshland and 169,613 ha is designated for agriculture (John, Wakilu, \& Olateju, 2013). Lagos state presented the perfect choice for the study as it has the highest literacy level $(96.30 \%)$ in Nigeria; and remains the focal point of Nigeria's economic and social development owing to its sea and airports (Nigeria Data Portal, 2016). In addition, it is the biggest spender on most non-food commodities like rent, fuel and lighting, household goods and transport, which reflects the high purchasing power of its populace (Mhango, 2013). It was therefore expected that Lagos state would have the highest level of consumers who are aware of, and use, food safety 
information in Nigeria.

\section{$2.2 \quad$ Source of Data}

Primary data was obtained via the use of pretested structured questionnaire from buyers of pre-packaged food in Lagos state. Using a confidence level of $95 \%$ and a confidence interval of $6.5,220$ food shoppers were found to be representative (from a population of 21 million people) for the study. Then, a two-stage sampling technique was used to select the sample of food shoppers. The first involved the selection of two shopping (Shoprite) malls from a list of five shopping (Shoprite) malls across Lagos state as they allowed their facilities to be used for data collection. Shoprite malls were used in the study because anecdotal evidence revealed they are the most widely accepted shopping malls in Lagos based on quality and prices of products sold. The second stage was the systematic selection of every fifth food shopper who purchases pre-packaged products until a population of 110 respondents were interviewed in each mall; this made a total of 220 food shoppers from each of the malls.

\subsection{Data Collection}

Data was collected from respondents using a structured questionnaire in an interview schedule. The questionnaire was split into three different sections:

- the first part aimed at assessing the socioeconomic characteristics of the consumer;

- the second, assessed the awareness and use of the different types of information on the food labels and which information is most utilised. It also obtained information on constraint to the use of food safety information; and

- the third part measured the factors that motivate consumers to read food safety information.

\subsection{Data Analysis}

Descriptive statistics were used to present the socio-economic characteristics of the respondents and the constraints to the use of food label information before food purchase. Cluster analysis was used to elicit the level of awareness and use of food safety labels, then presented using percentages and frequencies. Ordinal Regression Analysis was used to determine the factors influencing the frequency of reading food safety information contained food labels.

\section{Descriptive statistics}

The perception of a consumer's level of awareness and use of food safety labels was measured on a Likert scale. A scale ranging from 'never (1)' to 'always (5)' was used to measure the knowledge of those information cues printed on the food label. The mean of the responses from each respondent on each information cue was then obtained as a measure of the consumer's knowledge of the food safety information. Another scale ranging from 'Always (3)' to 'Never (1)' was used to elicit the level of use of those information cues. Then, the mean of the responses from each respondent on each information cue was obtained as a measure of that consumer's use of the food safety information. The information cues printed on food labels in Nigeria, according to NAFDAC, include: Product name, Brand name, Date of manufacture, Expire/best before date, Net quantity, Country of Origin, Ingredient list, Food additives, Name/address of manufacturer, Direction for use/storage, Warning statement, Health/nutrition claims, Information about allergens, Nutrition panel, and Trade mark.

In addition, a scale ranging from 'strongly agree (5)' to 'strongly disagree (1)' was used to measure the constraints to the use of food safety information contained in labels. This measure was obtained after calculating the mean of the responses by the respondents to the questions.

\section{Two-step Cluster Analysis}

A two-step cluster analysis was used to identify clusters of respondents based on their knowledge

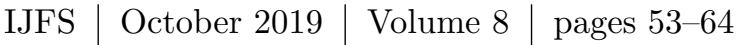


and use of the food safety information printed on the food labels during their purchase. The cluster analysis grouped the respondents into two based on their level of awareness and use of food safety information as done in the study by Talagala and Kalukottege (2015).

\section{Ordinal Regression Analysis}

Ordinal regression model is a type of regression model best suited for predicting the effects of independent variables on an ordinal dependent variable. It can be performed with the use of a generalized linear model (GLM) that fits both a coefficient vector and a set of thresholds to a dataset (McCullagh, 1980; Winship \& Mare, 1984). This model has also been used in other studies involving ordinal dependent variables (Lall, Campbell, J Walters, \& Morgan, 2002; Reddy \& Alemayehu, 2015). This was therefore used to obtain the determinants of frequency of reading food safety information. This model was selected due to the level of measurement of the dependent variable - frequency of reading food safety information, which was ordinal.

The respondents were asked, 'A variety of information is provided on food labels, how often you read them?' The responses were categorised into never, rarely, sometimes, and often. It is assumed that the alternative responses $(y)$ were related to a continuous, latent variable $\mathrm{y}^{*}$ that signified a respondent's frequency of reading food safety information. The answers to each statement were taken as the dependent variable in the ordinal regression model.

The model specification is given in equation 1

$$
\begin{aligned}
y_{i}^{*}= & \beta_{0}+\beta_{1} X_{1 i}+\beta_{1} X_{2}+\beta_{3} X_{3}+ \\
& \beta_{4} X_{4}+\beta_{5} X_{5}+\beta_{6} X_{6}+\beta_{7} X_{7}+\beta_{8} X_{8}+ \\
& \beta_{9} X_{9}+\beta_{10} X_{10}+\beta_{11} X_{11}+\beta_{12} X_{12}+\varepsilon_{i}
\end{aligned}
$$

Where 0 if $\mathrm{y}^{*}$ is never; $\mathrm{y}=1$ if $\mathrm{y}^{*}$ is rarely; 2 if $\mathrm{y}^{*}$ is sometimes; 4 if $\mathrm{y}^{*}$ is always.

$\beta_{0}=$ Constant; $\beta_{i}=$ Regression coefficients of the ith independent variable; $\mathrm{X}_{1 i}=$ Marital status (i could be Single - 1, Married, Divorce, Cohabiting partners or Widowed); $\mathrm{X}_{2}=\operatorname{Sex}(1=$ Male; $0=$ female); $\mathrm{X}_{3}=$ Age (years); $\mathrm{X}_{4}=$
Occupation/Sector (nominal); $\mathrm{X}_{5}=$ Perceived severity of food safety issues (continuous); $\mathrm{X}_{6}$ $=$ perceived vulnerability to food safety issues (continuous); $\mathrm{X}_{7}=$ response efficacy (continuous); $\mathrm{X}_{8}=$ self-efficacy (continuous); $\mathrm{X}_{9}=$ Frequency of shopping (categorical variable); $\mathrm{X}_{10}=$ Awareness of food safety information (continuous); $\mathrm{X}_{11 i}=$ Educational status of respondent (i $=$ No formal education, primary education, secondary education or tertiary education); $\mathrm{X}_{12}=$ Use of food safety information (continuous); $\varepsilon_{i}$

\subsection{Measurement of Variables}

The variables - perceived severity of food safety issues, perceived vulnerability to food safety issues, response efficacy, and self-efficacy were the measure of the psychosocial factors that could influence the frequency of reading food labels. These are constructs from the Protection Motivation Theory postulated by Rogers (1975). The theory has been used to explain consumer intention to consume foods in several health related studies (Floyd, Prentice-dunn, \& Rogers, 2000). Three of the constructs (Perceived severity of Food Safety Issues, Perceived Vulnerability to Food Safety Issues, and Response Efficacy) were measured using consumers' responses to three items on a scale of 1 (strongly disagree) to 5 (strongly agree), while Self-efficacy was measured using their responses to two items on a scale of 1 (strongly disagree) to 5 (strongly agree).

\section{Perceived severity of Food Safety Issues $\left(\mathrm{X}_{5}\right)$}

The respondents were asked to state their perception about the following statements: 'food safety incidents occur frequently in Nigeria'; 'unsafe food is widely spread in Nigeria food system'; and 'people's health is at risk due to unhealthy food'. The mean of the responses from each respondent was then used as the measure of the respondent's perceived severity of food safety issues. 


\section{Perceived Vulnerability to Food Safety Issues $\left(\mathrm{X}_{6}\right)$}

The respondents were asked to state their perception about the following statements: 'my health is at risk due to unhealthy food'; 'it is quite I possible I will ever get unsafe food'; and 'my health risk is highly related to food safety'. The mean of the responses from each respondent was then used as the measure of the respondent's perceived vulnerability to food safety issues.

\section{Response Efficacy $\left(\mathbf{X}_{7}\right)$}

The respondent's perceptions were obtained from their responses to the following statements: 'reading these food safety labels helps prevent choosing unsafe food'; 'these food safety labels provide me with useful information on purchasing safe food'; and 'reading these food safety labels relieves my concern about food safety'. The mean of the responses from each respondent was then used as the measure of the respondent's response efficacy to food safety issues.

\section{Self-efficacy $\left(\mathrm{X}_{8}\right)$}

The respondents were asked to state their perception - on a scale of 1 (strongly disagree) to 5 (strongly agree) - about the following statements: 'it is easy for me to read these food labels before purchasing food'; and 'I feel confident in my capability to study these food labels before purchasing food'. The mean of the responses from each respondent was then used as the measure of the respondent's self-efficacy to food safety issues.

\section{The Frequency of Shopping $\left(\mathrm{X}_{9}\right)$}

This was measured as a categorical variable. The respondents were asked to respond how frequently they went on food shopping: whether daily, at least twice a week, fortnightly, or monthly.

\section{Awareness of Food Safety Information $\left(\mathbf{X}_{10}\right)$}

Consumers' awareness was obtained from their responses to their level of awareness about the 14 information cues available on most food labels in Nigeria as stated earlier on a 5-point Likert scale.

\section{Use of Food Safety Information $\left(\mathbf{X}_{12}\right)$}

This was also measured on a 3 -point Likert scale using the same set of information cues used for awareness of food safety information.

\section{Results and discussion}

\subsection{Socio-economic characteristics of Respondents}

A total of 220 respondents took part in this study as shown in Table 1 . The study revealed that males made up a larger proportion $(58.2 \%)$ of the shoppers of pre-packaged food that were interviewed.

The age distribution of the respondents was within the youth bracket with the largest proportion $(61.6 \%)$ being 19 to 29 years old. The food shoppers were made up of $82.3 \%$ single persons and only about $20.5 \%$ of the food shoppers had a child or children.

The study also revealed that about $99 \%$ of the respondents had at least a secondary education with $53.5 \%$ either presently in a tertiary institution or had completed tertiary education. This was reflective of the high literacy rate in Lagos state. It also revealed that $51.6 \%$ of the respondents were technical and professional workers and about $34.4 \%$ unemployed.

On the frequency of food shopping, the largest proportion of the respondents $(29.6 \%)$ claimed to go food shopping at least twice a week.

\subsection{Awareness and Use of Food Safety Information}

The 2-step cluster analysis of the awareness and use of food safety information identified two broad categories within which each respondent fell. The clusters as shown in table 2 were high level of awareness and high use of food safety information and high level of awareness and low use of food safety information.

The study revealed that $61.8 \%$ had high level of awareness and high use of the information 
Use of food labels in Nigeria $\mid 59$

Table 1: Socio-economic Characteristics of Respondents

\begin{tabular}{|c|c|c|}
\hline Variable & Frequency & Percent \\
\hline \multicolumn{3}{|l|}{ Sex of consumer } \\
\hline Female & 92 & 41.6 \\
\hline Male & 128 & 57.9 \\
\hline \multicolumn{3}{|l|}{ Age distribution of consumer } \\
\hline$<=18$ & 19 & 8.6 \\
\hline $19-29$ & 130 & 58.8 \\
\hline $30-40$ & 54 & 24.4 \\
\hline $41-51$ & 7 & 3.2 \\
\hline $52+$ & 1 & 0.5 \\
\hline \multicolumn{3}{|l|}{ Marital status of consumer } \\
\hline Single & 181 & 81.9 \\
\hline Married & 39 & 17.6 \\
\hline \multicolumn{3}{|l|}{ Is the consumer a parent? } \\
\hline No & 175 & 79.2 \\
\hline Yes & 45 & 20.3 \\
\hline \multicolumn{3}{|l|}{ Educational status of consumer } \\
\hline Primary education & 2 & 0.9 \\
\hline Secondary education & 30 & 13.6 \\
\hline Tertiary education & 117 & 52.9 \\
\hline Postgraduate education & 70 & 31.7 \\
\hline \multicolumn{3}{|l|}{ Occupation of consumer } \\
\hline Unemployed & 76 & 34.4 \\
\hline Technical and Professional Workers & 113 & 51.1 \\
\hline Sales workers & 2 & 0.9 \\
\hline Transport workers & 6 & 2.7 \\
\hline Agricultural workers & 1 & 0.5 \\
\hline Artisans and Craftsmen & 18 & 8.1 \\
\hline Administrative and managerial workers & 3 & 1.4 \\
\hline \multicolumn{3}{|l|}{ Frequency of food shopping } \\
\hline Monthly & 61 & 27.6 \\
\hline Fortnightly & 56 & 25.3 \\
\hline At least twice a week & 64 & 29.0 \\
\hline Daily & 36 & 16.3 \\
\hline
\end{tabular}

Table 2: Cluster analysis for the awareness and use of food safety information

\begin{tabular}{lll}
\hline Clusters & High-high & High-low \\
\hline Size & $61.8 \%(136)$ & $38.2 \%(84)$ \\
\hline \multicolumn{3}{c}{ Source: Field Survey, 2017}
\end{tabular}

IJFS | October 2019| Volume 8| pages 53-64 
60 Danilola et al.

cues on food labels, whereas $38.2 \%$ fell in the second category of high level of awareness but low use of the information cues on food labels. This confirmed the finding of similar studies (Affram \& Darkwa, 2015; Basarir, 2012; Van der Merwe, Bosman, \& Ellis, 2014) where consumers reported high level of use of food labels before making food purchases.

The high level of awareness was reflective of the literacy rate of the respondents, while the low level of use in some quarters could have been due to the low level of trust on food labels to provide information on food safety.

\subsection{Factors Influencing the Frequency of Reading Food Safety Information on Food Labels}

The frequency of reading food label is indicated in Table 3 : of the 220 respondents (15 missing items) only $3.9 \%$ never read food labels. Many of the consumers read food labels; hence producers/processors should ensure the labels are clear enough for easy comprehension.

To check the reliability of the constructs of Protection Motivation Theory, the Cronbach alpha test was conducted on the different constructs (Table 4 ).

The ordinal regression model was utilised to obtain the determinants of the frequency of reading food safety information by respondents before food purchases in the study area. Since the frequency of reading food labels is an ordinal variable, the ordinal regression model was the most appropriate model to be used. The dependent variable of the model was frequency of reading food label and the ranked alternatives were never, rarely, sometimes and often. The result of the model is given in Table 5 . Only the variables important to the model were presented in the table.

It can be deduced from the results that sex, secondary education, tertiary education, unemployment, technical and professional workers and transport workers were all significant. In addition, the response efficacy and awareness of food label information of consumers both positively influenced the frequency of reading food safety information on food labels.

By taking the exponent of the pooled estimate of each variable i.e. $\exp ^{\beta}$, the common odds ratio of each variable differing by one unit was obtained. Therefore, male consumers were 0.561 times less likely than females to be reading food safety information in food labels frequently. This was very closely related to the findings of Ezeh and Ezeh (2014) and Falola (2014), where it was reported that females read food labels more than males.

Consumers with secondary education were 0.247 times less likely to read food labels frequently, and those with tertiary education 0.44 times less likely to read food labels frequently, than consumers with postgraduate education. This was in consonance with the studies that showed the frequency/likelihood of reading food labels increases with increases educational attainment (Basarir, 2012; Falola, 2014). The unemployed consumers were $1.46 \times 10^{-9}$ times less likely, technical and professional workers $2.615 \times 10^{-9}$ times less likely and transport workers $4.34 \mathrm{x}$ $10^{-9}$ less likely, when compared with artisans and craftsmen, to read food safety information frequently.

The odds of reading food labels frequency by consumers would likely increase by 1.826 for every unit increase in the response efficacy of consumers to food safety threat. This is expected because as the consumers see the reading of food labels as one of several coping strategies against food safety threats, it would most probably result in increased frequency of reading food safety information.

The odds of reading food safety information was also expected to increase, but by a factor of 1.504 , for a unit increase in the awareness of food safety information. This is plausible as the awareness of food safety information makes consumers realise the importance of knowing what they eat, and this culminates in the habit of frequency reading food labels. 
Use of food labels in Nigeria $\mid 61$

Table 3: The frequency of reading food labels

\begin{tabular}{lll}
\hline $\begin{array}{l}\text { Frequency of reading } \\
\text { food labels }\end{array}$ & Frequency & Percentage \\
\hline Never & 8 & $3.9 \%$ \\
Rarely & 28 & $13.6 \%$ \\
Sometimes & 84 & $40.8 \%$ \\
Often & 86 & $41.7 \%$ \\
Valid & 206 & $100.0 \%$ \\
\hline
\end{tabular}

Table 4: Reliability Test for the Different Variables

\begin{tabular}{llll}
\hline S/N & Variable & Cronbach's Alpha & N of items \\
\hline 1 & Awareness of food safety information & 1.00 & 14 \\
2 & Use of food safety information & 1.00 & 14 \\
3 & Perceived severity of food safety threats & 0.56 & 3 \\
4 & Perceived vulnerability to food threats & 0.63 & 3 \\
5 & Perceived response efficacy & 0.73 & 3 \\
6 & Perceived self-efficacy & 0.72 & 2 \\
\hline
\end{tabular}

Table 5: Ordinal logistic regression analysis for the determinants of frequency of reading food labels

\begin{tabular}{llll}
\hline Variable $^{1}$ & Coefficient & Std. Error & Wald \\
\hline Sex & $-.579^{*}$ & .339 & 2.918 \\
Age & .031 & .036 & .714 \\
Marital status & -.528 & .655 & .648 \\
Secondary education & $-1.405^{* *}$ & .521 & 7.284 \\
Tertiary education & $-.817^{* *}$ & .367 & 4.961 \\
Unemployed & $-20.347^{* * *}$ & .593 & 1177.465 \\
Technical and professional workers & $-19.762^{* * *}$ & .548 & 1300.238 \\
Transport workers & $-19.255^{* * *}$ & 1.015 & 360.145 \\
Admin and managerial workers & -.639 & 7365.302 & .000 \\
Perceived Severity & .234 & .258 & .820 \\
Perceived Vulnerability & -.251 & .169 & 2.198 \\
Self-Efficacy & .051 & .205 & .062 \\
Response Efficacy & $.602^{* *}$ & .195 & 9.573 \\
Awareness of Food Label Information & $.408^{*}$ & .232 & 3.095 \\
Use of Food Label Information & .170 & .322 & .277 \\
\hline Log Likelihood function: 393.591; Chi squared: $71.095 .{ }^{*}$ : significant at 0.10 level; **: significant at 0.05 level; \\
***: significant at 0.01 level. \\
$\begin{array}{l}\text { 1 The reference variables for secondary and tertiary } \\
\text { status is the artisan and craftsmen }\end{array}$
\end{tabular}

IJFS | October $2019 \mid$ Volume $8 \mid$ pages 53-64 
$62 \mid$ Danilola et al.

Table 6: Constraints to the Reading of Food Safety Labels

\begin{tabular}{lll}
\hline Constraints & Mean score & Rank \\
\hline Buying familiar foods & 3.54 & $1^{\text {st }}$ \\
Smallness/illegible prints & 3.36 & $2^{\text {nd }}$ \\
Lack of time & 3.30 & $3^{\text {rd }}$ \\
Positioning of food labels & 3.15 & $4^{\text {th }}$ \\
Interpreting food label information & 3.14 & $5^{\text {th }}$ \\
Health issues & 3.10 & $6^{\text {th }}$ \\
Importance & 2.75 & \\
\hline
\end{tabular}

\subsection{Constraints to Consumers' Awareness and Use of Food Safety Information}

Consumers are faced with some challenges to the use of food safety information in food labels. Table 6 shows the constraints faced by the respondents.

The respondents perceived buying of familiar foods as the major constraints to the reading of food safety information on food labels. This is due to the belief that they have checked out the food label in the past and don't expect significant change in the product information in the current purchase, although they check for the expiry/best before date in some products. In addition, the respondents also identified smallness/illegibility of most food label prints and lack of time to go through them as constraints to the reading of food labels. As a result, producers of pre-packaged food are advised to ensure the print is clear enough for the consumers to read without stress and that these labels should contain concise information for them to read in little time. On the flip side consumers did not believe food labels are unimportant as seen by the mean score (2.75) being below the passing score (3.00).

\section{Conclusions}

This study examined consumers' awareness and use of food safety information among food shoppers in Lagos state. Primary data were collected by means of interview schedule through the use of a structured questionnaire. Data were analysed using descriptive statistics, cluster analysis, and ordinal regression model. A large percentage of the shoppers of pre-packaged were aware of food safety information on food labels. However, a cluster analysis of the respondents showed that only about $61.8 \%$ of consumers accorded high importance to the awareness and use of food safety information.

Analysis from the ordinal regression model showed that female, more educated consumers, and those consumers who are artisans and craftsmen were more likely to read food labels frequently. It also showed that the frequency of reading food labels could be increased among the consumers with increased response efficacy to food safety threat and awareness of food safety information. The habit of buying familiar food is a constraint to reading food labels for the average food shopper. Based on the findings of this research, it can be concluded that a large percentage of the food shoppers are aware of food safety information present on food labels but only few use them to inform purchases.

The following recommendations would be made to policy makers and other relevant stakeholders based on the findings of the research:

Educational and awareness programmes encouraging food consumers to pay closer attention to the use of food labels beyond just the product name and expiry date as food labels. This would help maximise the use of the contents of food labels especially the health and nutrition claims as consumers also check labels for health reasons. Stakeholders on food labelling should address the challenges faced by consumers in the utilisation of food labels especially on the illegibility 
of prints. Although buying familiar food seems not like an issue but legibility of print and time constraints are big issues in the reading and use of food labels.

\section{References}

Affram, P. C., \& Darkwa, S. (2015). Consumers' knowledge, understanding and use of food label information, and how it affects purchasing decision in ho, ghana. 5, 24-39.

Ali, J., \& Kapoor, S. (2009). Understanding consumers' perspectives on food labelling in india. 33, 724-734.

Basarir, A. (2012). Consumers awareness of food labeling: A case study of united arab emirates. African Journal of Agricultural Reseearch, $\%$.

David, M. (2009). Nigeria food and agricultural import regulations and standards narrative fairs country report. Global Agricultural Information Network, USDA Foreign Agricultural Science. Retrieved from https : / / gain . fas . usda. gov / Recent \% 20GAIN\% 20Publications / Food \% 20and \% 20Agricultural \% 20Import \% 20Regulations $\%$ 20and $\%$ 20Standards $\% 20$ \%20Narrative_Lagos_Nigeria_12 - 30 - 2016 . pdf

Du Plessis, P. J., \& Rousseau, D. (2003). Buyer behaviour: A multi-cultural approach. Oxford University Press.

Ezeh, O. H., \& Ezeh, C. C. (2014). Knowledge and attributes of students in middle level agricultural institutions in nigeria towards information on food labels. African Journal for the Psychological Study of Social Issues, 19(1), 60-69. Retrieved from https://www. ajol.info/index.php/ajpssi / article/view / 136906

Falola, A. (2014). Towards nutrition security: Food label use among nigerians. International Journal of Food and Agricultural Economics (IJFAEC), 2(1128-201692040), 127.

Floyd, D. L., Prentice-dunn, S., \& Rogers, R. W. (2000). A meta-analysis of research on protection motivation theory. 30, 407-429.
Grunert, K. G., \& Wills, J. M. (2007). A review of european research on consumer response to nutrition information on food labels. 15, 385-399.

Henson, S., \& Caswell, J. A. (1999). Food safety regulation: An overview of contemporary issues. 24, 589-603.

John, O., Wakilu, O., \& Olateju, A. (2013). Gricultural information needs of farmers in lagos state, nigeria. International Journal of Agricultural Science Research, 2(4), 116-123. Retrieved from http: / / www . academeresearchjournals . org / download . php?id=512782439154739916.pdf

Kaur, V., Nirmal Kaur, D. R., \& Neha Qumar, M. S. (2016). Assesment of consumer awareness about usage of food labels and its impact on food buying behaviour. 4, 10 19.

Lall, R., Campbell, M., J Walters, S., \& Morgan, K. (2002). A review of ordinal regression models applied on health related quality of life assessments. 11, 49-67.

Lawal, M. O., \& Aliu, I. R. (2012). Bulletin of geography. In D. Szymańska \& J. Biegańska (Eds.), (Chap. Operational pattern and contribution of urban farming in an emerging megacity: evidence from Lagos, Nigeria, pp. 87-97). doi:10.2478/v10089-012-0009-1

McCullagh, P. (1980). Regression models for ordinal data. 42.

Mhango, Y. (2013). Nigeria unveiled, thirty-six shades of nigeria. A thematic research. Retrieved from https://im.ft-static.com/ content/images/5752734c-c2f4-11e2-bbbd00144feab7de.pdf

Naspetti, S., \& Zanoli, R. (2009). Organic food quality and safety perception throughout europe organic food quality and safety perception. 15, 249-266.

Nigeria Data Portal. (2016). Retrieved from www.opendataforafrica.org

Ortega, D., Wu, L., Wang, H., \& Widmar, N. (2011). Modeling heterogeneity in consumer preferences for select food safety attributes in china. 36, 318-324.

Reddy, O. C., \& Alemayehu, E. (2015). Ordinal logistic regression analysis to assess the factors that affect health status of students in ambo university: A 
$64 \mid$ Danilola et al.

case of natural and computational sciences college, ambo university. International Journal of Modern Chemistry and Applied Science, 2(2), 153-163. Retrieved from http:// www . ijcasonline. com / images / Ordinal \% 20logistic \% 20regression\%20analysis\%20to\%20assess\% 20the \% 20factors \% 20that \% 20affect \% 20health \% 20status \% 20of \% 20students \% 20in $\%$ 20ambo $\%$ 20university $\%$ 20a $\%$ 20case $\%$ 20of \% 20natural \% 20and \% 20computational \% 20sciences \% 20college , \%20ambo\%20university..pdf

Rijswijk, W., \& Frewer, L. (2008). Consumer perceptions of food quality and safety and their relation to traceability. 110.

Rogers, R. W. (1975). A protection motivation theory of fear appeals and attitude change1. The Journal of Psychology, 91 (1), 93-114. PMID: 28136248. doi:10 . 1080/ 00223980.1975.9915803

Smith, D., \& Riethmuller, P. (2000). Consumer concerns about food safety in australia and japan. 102, 838-855.

Talagala, T. S., \& Kalukottege, C. J. P. (2015). Factors associated with consumers awareness and use of information on food labels.

Van der Merwe, D., Bosman, M., \& Ellis, S. (2014). Consumers' opinions and use of food labels: Results from an urban-rural hybrid area in south africa. 63, 100-107.

Winship, C., \& Mare, R. D. (1984). Regression models with ordinal variables. 49,512 .

Wyma, L., Van der Merwe, D., Bosman, M., Erasmus, A., Strydom, H., \& Steyn, F. (2012). Consumers preferences for private and national brand food products. 36, 432439. 